\title{
Insulin Enhancement of Cytokine-Induced Coagulation/ Inflammation-Related Gene Transcription in Hepatocytes
}

\author{
MizUHO OKAZAKI, YASUMASA IWASAKI, HE JING, MiTSURU NISHIYAMA, TAKAFUMI TAGUCHI, \\ MAKOTO TSUGITA, YOSHINORI TANIGUCHI, MACHIKO KAMBAYASHI AND KOZO HASHIMOTO \\ Department of Endocrinology, Metabolism, and Nephrology, Kochi Medical School, Kochi University, Kohasu, Oko-cho, Nankoku \\ 783-8505, Japan
}

\begin{abstract}
Hyperinsulinemia is a known risk factor for cardiovascular events, but its molecular basis is not completely understood. In this study, we examined the effects of insulin alone, or insulin and proinflammatory cytokines, on the expression of inflammation/coagulation-related genes in hepatocytes. We found that, in the HepG2 human hepatocyte cell line, insulin stimulated the transcriptional activity of plasminogen activator inhibitor 1 (PAI-1), fibrinogen- $\gamma$ and C-reactive protein (CRP) genes in time- and dose-dependent manners. These effects were completely inhibited by MAP kinase inhibitor PD98059, but not by PI3 kinase inhibitor wortmannin. As previously reported, proinflammatory cytokines like interleukin $1 \beta$ and interleukin 6 showed stimulatory effects on the expression of these genes, and we now found that the combination of insulin and the cytokines showed more than additive effects in most cases. Interleukin $1 \beta$ and insulin also cooperatively increased the endogenous mRNA level of PAI-1. These results suggest that the coexistence of high insulin and cytokines may induce inflammation and hypercoagulation in a synergistic manner. This may partly explain why the accumulation of multiple risk factors, especially hyperinsulinemia caused by insulin resistance and enhanced production of proinflammatory cytokines, results in inflammation, thrombosis, and cardiovascular events in metabolic syndrome.
\end{abstract}

Key words: Coagulation, Inflammation, Cytokine, Metabolic syndrome

(Endocrine Journal 55: 967-975, 2008)

IN recent years, the accumulation of multiple metabolic risk factors such as obesity, dyslipidemia, glucose intolerance, and hypertension has been linked with the high prevalence of cardiovascular events, and is now recognized as the metabolic syndrome [1]. It has also been shown that the pivotal feature of the syndrome is insulin resistance (with hyperinsulinemia) [2] and overproduction of proinflammatory cytokines, derived systemically from the visceral adipose tissue such as adipokines or locally from the vascular wall [3]. Metabolic syndrome has now come to be recognized as a proinflammatory state, and is frequently associated

Received: March 11, 2008

Accepted: June 9, 2008

Correspondence to: Yasumasa IWASAKI, M.D., Ph.D., Department of Endocrinology, Metabolism, and Nephrology, Kochi Medical School, Kochi University, Kohasu, Oko-cho, Nankoku 783-8505, Japan with hypercoagulability. Indeed, the plasma levels of C-reactive protein (CRP), and clotting factors like fibrinogen and the inhibitor of fibrinolysis, like plasminogen activator inhibitor 1 (PAI-1), have been shown to be increased in this disorder, and the latter may be at least partly responsible for the high prevalence of thrombotic disorders in the syndrome [4]. However, the molecular mechanism whereby the combination of multiple risk factors, especially insulin resistance and cytokine overproduction, causes the hypercoagulative state is not completely understood.

In this study, we examined the effects of insulin alone, as well as insulin and proinflammatory cytokines like interleukin- $1 \beta$ (IL-1 $\beta$ ) and -6 (IL-6), on the expression of coagulation/inflammation-related genes such as PAI-1, fibrinogen- $\gamma$, and CRP, using the human hepatocyte cell line HepG2 in vitro. We found that the combination of insulin and cytokines has potent stimulatory effects on the transcription of 
these genes in a additive/synergistic manner, which may partly explain the reason why co-existence of insulin resistance and visceral obesity causes inflammation, thrombosis, and cardiovascular events in metabolic syndrome.

\section{Materials and Methods}

\section{Reagents}

Human insulin was provided by Eli Lilly (Indianapolis, IN). IL-1 $\beta$ and IL-6 were purchased from PeproTech (Rocky Hill, NJ), and PD98059 and wortmannin were from Calbiochem (San Diego, CA) and Sigma (St. Louis, MO), respectively.

\section{Plasmids}

The 5'-promoter region of the human PAI-1 (-687/ +142 bp), fibrinogen- $\gamma(-1000 /+1 \mathrm{bp})$, and CRP (-184/ $+43 \mathrm{bp}$ ) were cloned by PCR and incorporated into the pA3Luc luciferase reporter plasmid using standard molecular biology techniques. pNF-кB-Luc and pAP1Luc, containing tandem repeat of the consensus NF$\kappa \mathrm{B}$ and $\mathrm{AP} 1$ sequences, respectively, were obtained from Clontech (Mountain View, CA).

\section{Cell culture and experiments}

The human hepatoma HepG2 cells were maintained in DMEM (Sigma) supplemented with $10 \%$ fetal bovine serum (FBS) and penicillin/streptomycin under a $5 \% \mathrm{CO}_{2} / 95 \%$ air atmosphere at $37^{\circ} \mathrm{C}$. In each experiment, cells were plated and cultured in 24-well plates to $50 \%$ confluency. On the next day the cells were transfected with the test plasmids and human insulin receptor expression vector using FuGene 6 transfection reagent (Roche, Indianapolis, IN), and $24 \mathrm{~h}$ later the medium was changed to serum-free medium. In each experiment, test reagents, in $1000 \times$ concentration, were then added directly into the culture medium, and the cells were incubated for the defined time interval. At the end of incubation, the culture medium was removed, and the cells were harvested for the determination of luciferase activity.

\section{Luciferase assay}

Luciferase assay was performed as previously described [5], and light output was measured for $20 \mathrm{sec}$ at room temperature using a luminometer (Berthold Lumat LB9507, Bad Wildbad, Germany).

\section{$R T-P C R$}

Endogenous expression of PAI-1, fibrinogen- $\gamma$, and CRP mRNAs in HepG2 cells was examined by RTPCR. The cells were plated in 3.5-cm-diameter dishes, and total RNA was extracted using RNeasy RNA extraction kit (Qiagen, Hilden, Germany). One $\mu$ g each was then applied for reverse transcription reaction using Superscript III reverse transcriptase (Invitrogen, Carlsbad, CA), followed by PCR reaction (25-30 cycles, $94^{\circ} \mathrm{C} 30 \mathrm{sec}, 60^{\circ} \mathrm{C} 30 \mathrm{sec}, 72^{\circ} \mathrm{C} 2 \mathrm{~min}$ ) using Blend Taq DNA polymerase (Toyobo, Tokyo, Japan). The primer sets used were: human PAI-1 sense 5'CAGACGCGATCTTCGTCCAG-3', antisense 5'-GCA GCAATGAACATGCTGAGG-3'; human fibrinogen- $\gamma$ sense 5'-CAACATGTGTAGCATATGTTGC-3', antisense 5'-GACCCATCGATTTCACAGTAG-3'; and human CRP sense 5'-GAGAAGCTGTTGTGTTTCT TGG-3', antisense 5'-CATGTTCACATTTCCAATG TCTC-3'. All the primer sets were designed as intronspanning to distinguish the cDNA-derived PCR product from that of the genomic DNA-derived one.

\section{Quantitative RT-PCR}

Reagents, software, and equipment were from Applied Biosystems (Foster City, CA). TaqMan reactions were performed using TaqMan universal PCR master mix and the ABI PRISM 7700 sequence detection system, and analysis was performed using the sequence detection system software. Human PAI-1 TaqMan probes were also from Applied Biosystems (Hs00167155 m1). Human GAPDH mRNA was used as an internal control (Hs99999905 ml). The quantity of the target mRNA in an unknown sample was determined from the $\mathrm{Ct}$ value using the standard curve. A control without a template was included in each experiment. Non-template controls, standard dilutions, and samples were assayed in duplicate. 


\section{Statistical Analysis}

Samples in each group of the experiments were in triplicate or quadruplicate. All data were expressed as mean $\pm \mathrm{SEM}$. When the statistical analyses were performed, data were compared by one way analysis of variance with Fisher's multiple range test, and $\mathrm{P}$ values below 0.05 were considered significant.

\section{Results}

Endogenous expression of $m R N A s$ related to the coagulation/inflammation genes in HepG2 cells

The intrinsic expression of PAI-1, fibrinogen- $\gamma$, and CRP was analyzed by RT-PCR. As shown in Fig. 1, mRNAs for all genes were amplified, indicating that this cell line is appropriate for the transcriptional regulation of these genes in vitro.

Time-course effects of insulin on the expression of coagulation/inflammation-related genes

We examined the effect of insulin on the transcriptional activity of the inflammation/coagulation-related genes. As shown in Fig. 2, insulin enhanced the 5'promoter activity of these genes in a time-dependent manner. A significant effect was obtained at $24 \mathrm{~h}$ (PAI-1, fibrinogen- $\gamma$ ) and $48 \mathrm{~h}$ (CRP).

Effects of protein kinase inhibitors on the insulin effect on coagulation/inflammation-related genes

We then examined the effect of kinase inhibitors on the insulin stimulation of the inflammation/coagulation-related gene transcription. As shown in Fig. 3, the enhancing effects of insulin on the 5'-promoter activity of all genes were completely abolished in the presence of MAP kinase kinase (MEK) inhibitor PD98059 $(20 \mu \mathrm{M})$ but were not influenced by PI3 kinase (PI3K) inhibitor wortmannin $(1 \mu \mathrm{M})$, suggesting the involvement of the former signaling pathway.

Time-course effects of IL-1 $1 \beta$ on the expression of coagulation/inflammation-related genes

We also examined the effect of IL- $1 \beta$ on the transcriptional activity of the inflammation/coagulation-

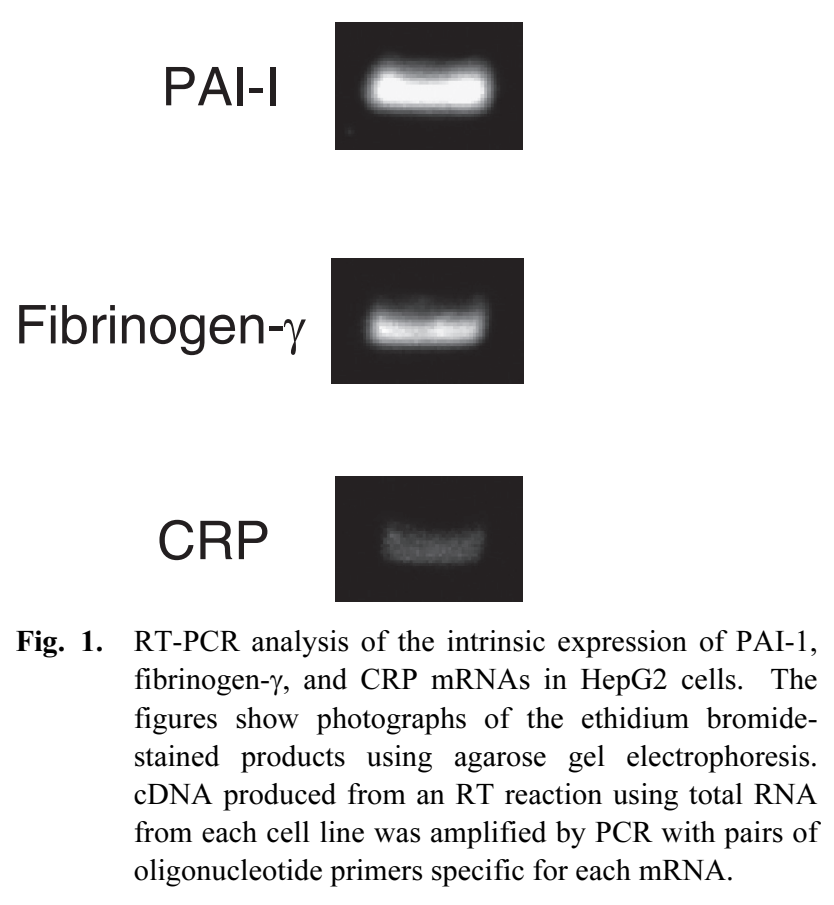

related genes. As shown in Fig. 4A, IL-1 $\beta$ enhanced the 5'-promoter activity of these genes in a timedependent manner. A significant effect was obtained at $12 \mathrm{~h}$ (PAI-1) and $48 \mathrm{~h}$ (fibrinogen- $\gamma, \mathrm{CRP})$.

Time-course effects of IL-6 on the expression of coagulation/inflammation-related genes

The effects of IL6 were also examined. As shown in Fig. 4B, IL-6 enhanced the 5'-promoter activity of these genes in a time-dependent manner. A significant effect was obtained at $12 \mathrm{~h}$ (fibrinogen- $\gamma, \mathrm{CRP}$ ) and 24 h (PAI-1).

Combined effects of insulin and IL-1 $\beta$ on the expression of coagulation/inflammation-related genes

We then examined the crosstalk between insulin and cytokine signaling pathways. As shown in Fig. 5A, insulin and IL-1 $\beta$, when treated alone, showed significant positive effects on the transcriptional activity of each gene, similar to the previous experiments. Furthermore, when used in combination, an additive effect was observed in PAI-1 gene, and more than additive (synergistic) effects were observed in fibrinogen- $\gamma$ and CRP genes. 

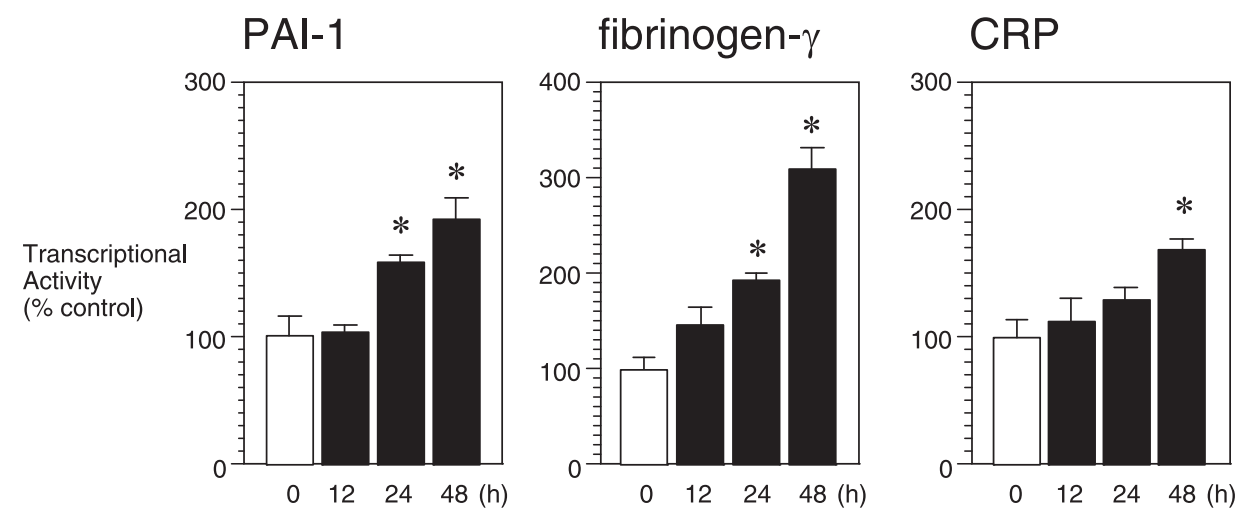

Fig. 2. Time-course effects of insulin on the transcriptional activity of PAI-1, fibrinogen- $\gamma$, and CRP. HepG2 cells were transfected transiently with each test plasmid and then treated with insulin $(10 \mathrm{nM})$ for $12-48 \mathrm{~h}$. Each value is shown as a percentage of the value at time zero. $* \mathrm{P}<0.05$ vs. value at time zero $(0)$.
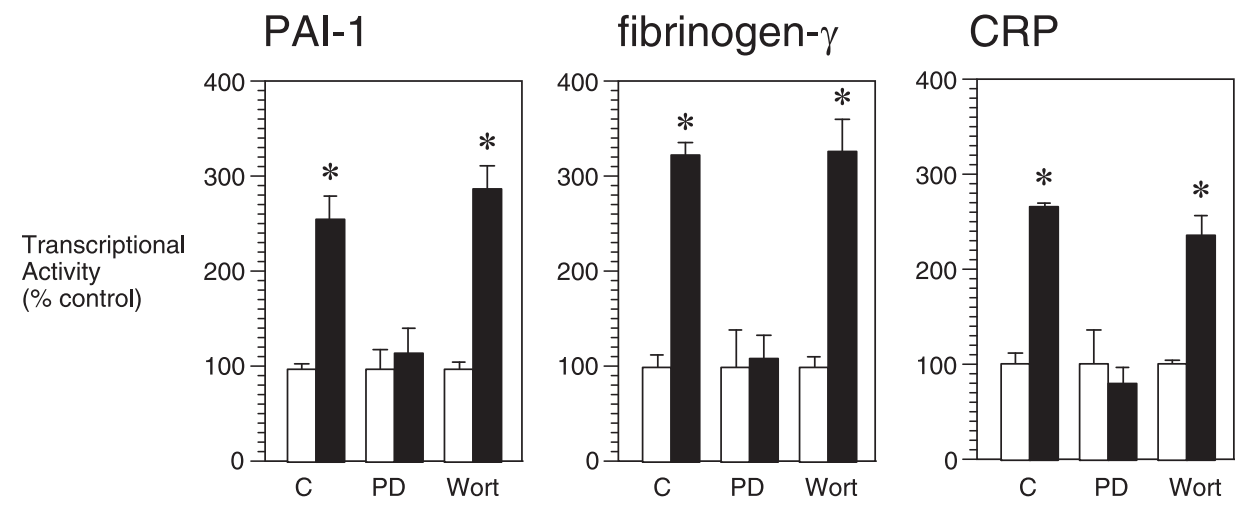

Fig. 3. Effects of kinase inhibitors on the insulin-induced transcriptional activity of PAI-1, fibrinogen- $\gamma$, and CRP. HepG2 cells were transfected transiently with each test plasmid and then treated with vehicle (open bars) or insulin (closed bars: $10 \mathrm{nM}, 48 \mathrm{~h}$ ). The cells were also treated with vehicle (C), PD98059 (PD; $20 \mu \mathrm{M}$ ), or wortmannin (Wort; $1 \mu \mathrm{M}$ ) from 30 min prior to the addition of insulin until the end of experiment. Each value is shown as a percentage of the corresponding control (no insulin). $* \mathrm{P}<0.05$ vs. corresponding control (no insulin).

\section{Combined effects of insulin and IL-6 on the expression of coagulation/inflammation-related genes}

The combined effects of insulin and IL-6 were also examined. As shown in Fig. 5B, insulin and IL-6, when treated alone, showed significant positive effects on the transcriptional activity of each gene, in accordance with the previous experiments. In addition, like the case with insulin and IL-1 $\beta$, more than additive (synergistic) effects were observed in all genes, amongst which the effect was most prominent in fibrinogen- $\gamma$.
Combined effects of insulin and IL-1B/IL-6 on the inflammation-related transcription factor-specific transcription

To determine the transcription factor(s) mediating the effects of IL $1 \beta / \mathrm{IL}-6$, we carried out an experiment using the two inflammation-related transcription factor-specific reporter plasmids, i.e. NF-kB-Luc and AP1-Luc. As shown in Fig. 6, the synergistic effect of insulin and IL-1 $\beta$, like other inflammation/coagulation-related genes, was observed in NF-kB-dependent, but not in AP1-dependent, transcription. On the other hand, no synergistic effect was observed in both NF$\kappa \mathrm{B}$ and AP1-dependent transcription when insulin and IL-6 were used. 
A
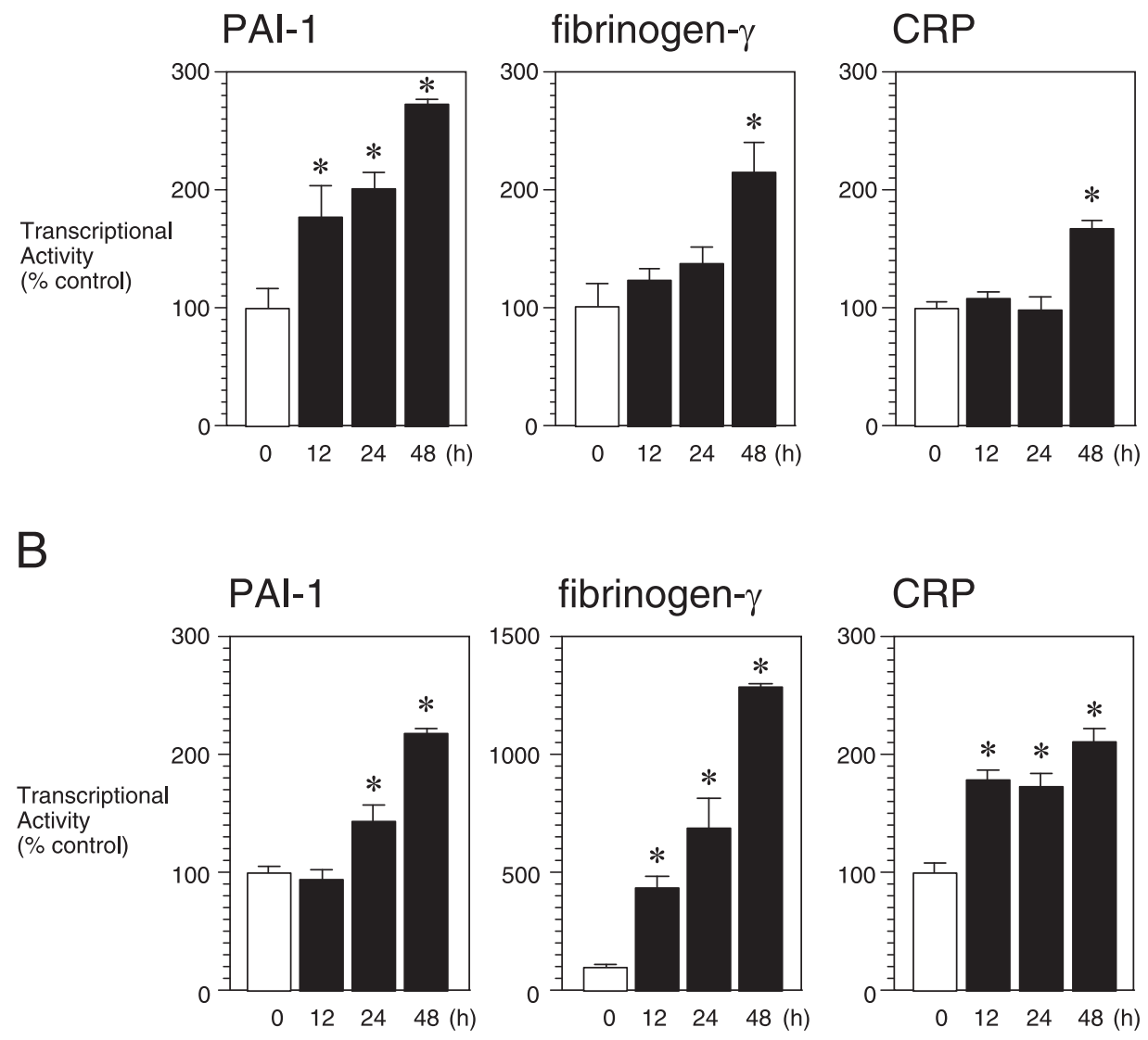

Fig. 4. Time-course effects of IL-1 $\beta$ and IL-6. A. HepG2 cells were transfected transiently with each test plasmid and were treated with IL-1 $\beta(1 \mathrm{nM})$ for $12-48 \mathrm{~h}$. B. HepG2 cells were transfected transiently with each test plasmid and then treated with IL-6 $(1 \mathrm{nM})$ for $12-48 \mathrm{~h}$. Each value is shown as a percentage of the value at time zero. $* \mathrm{P}<0.05$ vs. value at time zero $(0)$.

Combined effects of insulin and IL-1 $\beta$ on the endogenous expression of PAI-1 mRNA

Finally, we examined the combined effects of insulin and IL- $1 \beta$ on the endogenous expression of mRNA level by a quantitative RT-PCR technique, using a PAI-1 mRNA as a representative of inflammation/ coagulation-related genes. As shown in Fig. 7, insulin and IL- $1 \beta$, when treated alone, significantly increased the amount of PAI-1 mRNA. Furthermore, when used in combination, an additive effect was observed, similar to the results obtained using the PAI-1 promoter.

\section{Discussion}

In this study, we found that insulin, as well as proinflammatory cytokines such as IL- $1 \beta$ and IL-6, induces the transcription of coagulation/inflammation-related genes. Furthermore, the combination of insulin and these cytokines exerted additive or more than additive effects. This was also the case with the effect of IL- $1 \beta$ on endogenous expression of PAI-1 mRNA. Thus, we assume that the synergism in the effects of insulin and cytokines may partly explain why the accumulation of multiple risk factors, like insulin resistance with compensatory hyperinsulinemia and abdominal obesity with enhanced production of proinflammatory cytokines, is responsible for the occurrence of hypercoagulation/thrombosis and cardiovascular events in the metabolic syndrome.

Although the major role of insulin in the human is to regulate blood glucose level, the hormone was originally derived from a growth factor like insulin-like growth factor I (IGF-I). Indeed, intracellular insulin signaling has two major pathways, the insulin receptor 
A
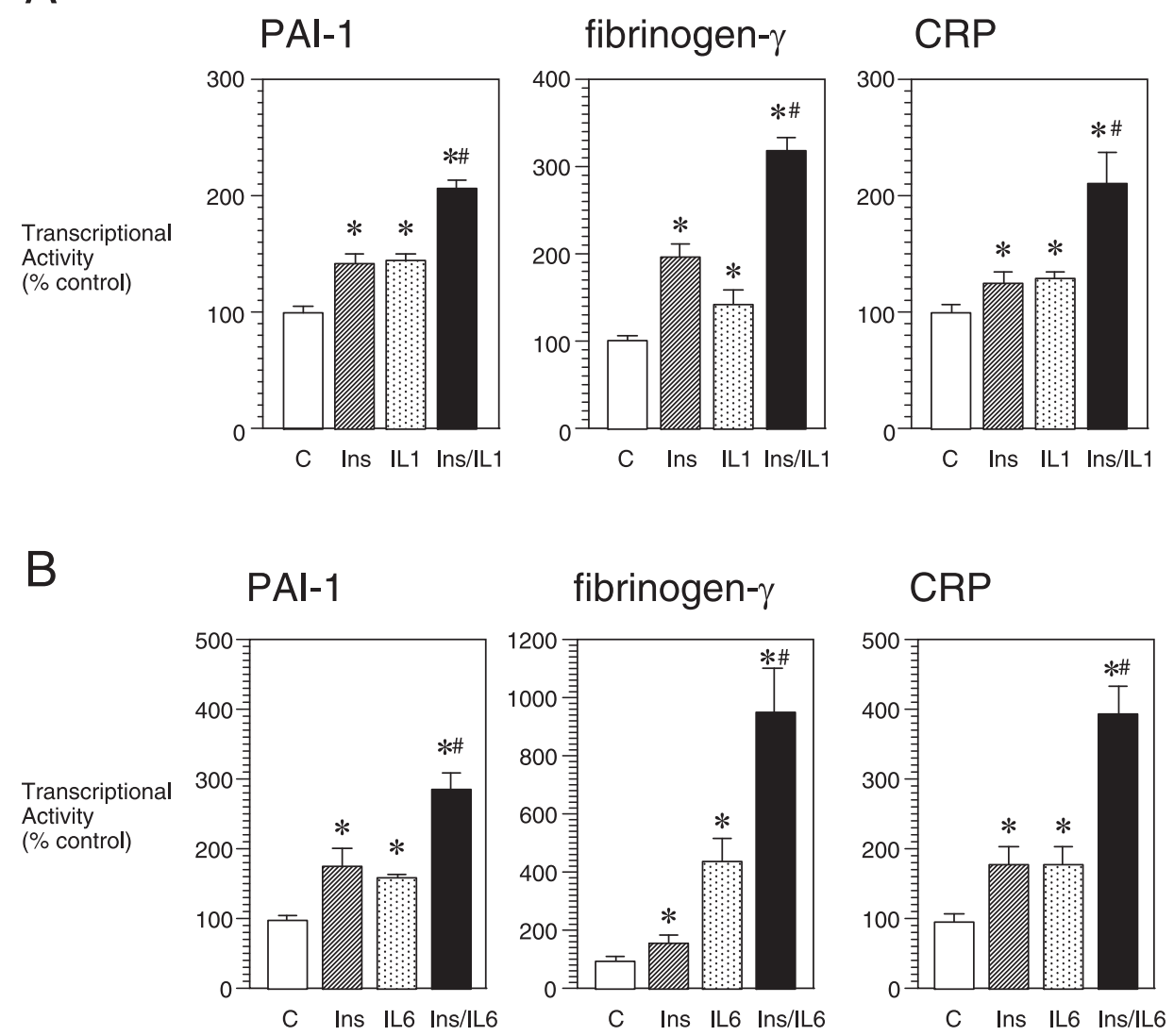

Fig. 5. Combined effects of insulin and IL-1 $\beta /$ IL-6. A. HepG 2 cells were transfected transiently with each test plasmid and then treated with insulin (Ins; $10 \mathrm{nM}, 48 \mathrm{~h}$ ), IL-1 $\beta$ (IL1; $1 \mathrm{nM}, 24 \mathrm{~h}$ ), or in combination. B. HepG2 cells were transfected transiently with each test plasmid and then treated with insulin (Ins; $10 \mathrm{nM}, 48 \mathrm{~h})$, IL-6 (1 nM, $24 \mathrm{~h})$, or in combination. ${ }^{*} \mathrm{P}<0.05$ vs. vehicle group (C). ${ }^{\#} \mathrm{P}<0.05$ vs. insulin alone group.

substrate (IRS)/PI3K/Akt-mediated metabolic pathway and the Ras/MEK/MAP kinase (MAPK)-mediated growth pathway [6]. Recent basic studies suggest that the insulin resistance in the metabolic syndrome exists in the IRS/PI3K/Akt pathway that regulates the glucose homeostasis, resulting in a compensatory hyperinsulinemia to maintain plasma glucose level. Since the signal transduction mediated by the Ras/MEK/ MAPK pathway is shown to be preserved [7-9], the increased plasma insulin simultaneously causes overstimulation of this pathway $[10,11]$. In our study, the effects of insulin on PAI- 1 , fibrinogen- $\gamma$, and CRP were completely abolished by the MEK inhibitor, but not by the PI3K inhibitor. Thus, we assume that the transcriptional regulation of these genes by insulin is under the control of the growth pathway of insulin signaling. Furthermore, the expression of these genes can be activated or even overstimulated in the state of insulin resistance with hyperinsulinemia in vivo.

It is of interest that insulin enhanced the effect of proinflammatory cytokines. Although the precise mechanism of the positive interaction between insulin and cytokine signaling is not clear in this study, molecular synergism may be occurring at the level of the single transcription factor, such as NF- $\mathrm{KB}$. Indeed, our results showed that more than additive effects of insulin and IL- $1 \beta$ were observed in NF- $\mathrm{NB}$-specific reporter gene transcription as well as in the promoters of inflammation/coagulation-related genes. Previous studies also have shown that NF- $\mathrm{KB}$ is involved in the transcription of PAI-1, fibrinogen, and CRP genes [12-16]. Since MAPK is known to enhance the transcriptional function of NF- $\mathrm{kB}$ via phosphorylation [17, 18], insulin may thus potentiate the cytokine-induced $\mathrm{NF}-\mathrm{\kappa B}$ transcription in this fashion. In contrast, no additive effect of insulin and IL- 6 on NF- $\mathrm{KB}$-dependent 
A
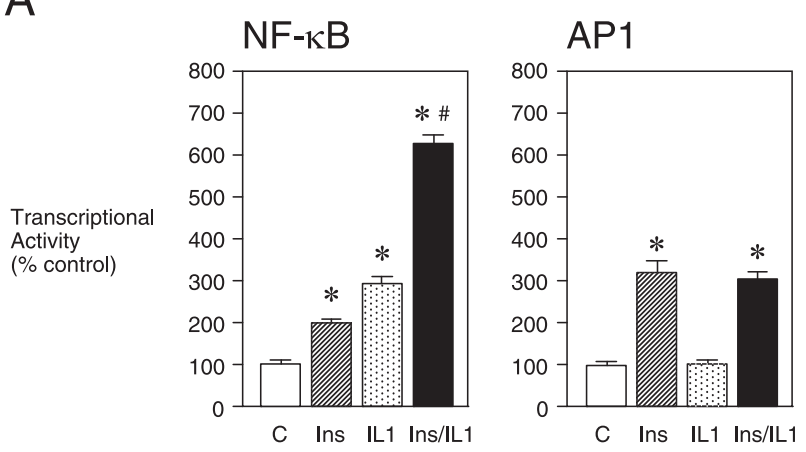

B

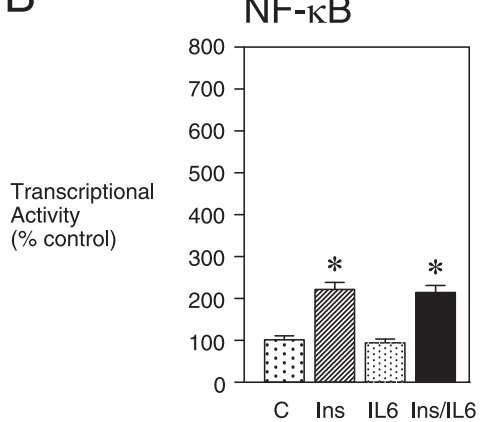

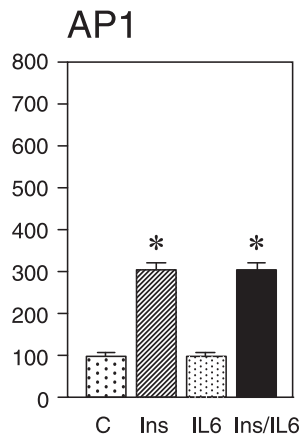

C Ins IL6 Ins/IL6

Fig. 6. Combined effects of insulin and IL-1 $\beta / \mathrm{IL}-6$ on the inflammation related transcription factors-dependent transcription. A. HepG2 cells were transfected transiently with NF-kB-Luc or AP1-Luc reporter plasmids, and then treated with insulin (Ins; $10 \mathrm{nM}, 48 \mathrm{~h}$ ), IL-1 $\beta$ (IL1; $1 \mathrm{nM}, 24 \mathrm{~h}$ ), or in combination. B. HepG2 cells were transfected transiently with the same plasmids as $\mathrm{A}$, and then treated with insulin (Ins; $10 \mathrm{nM}, 48 \mathrm{~h}$ ), IL-6 $(1 \mathrm{nM}, 24 \mathrm{~h})$, or in combination. ${ }^{*} \mathrm{P}<0.05$ vs. vehicle group (C). ${ }^{\#} \mathrm{P}<0.05$ vs. insulin alone group.

transcription was observed, suggesting the involvement of transcription factor(s) other than NF- $\kappa B$.

Another possible mechanism of molecular synergism is the cooperative effect of multiple transcription factors. Transcriptional regulation is mediated not only by transcription factors themselves but also by transcriptional cofactors, and the recruitment depends on the type and context of the transcription factors on the promoter. In addition to NF- $\kappa B$, other inflammation-related transcription factors such as AP1, HIF-1, C/EBPs, and STAT3 are shown to be involved in the transcription of PAI-1, fibrinogen, and CRP genes [19-23], and it is possible that a specific cofactor(s) is recruited only when multiple transcription factors are simultaneously activated by the combined stimulation of insulin and cytokines.

Our in vitro results may underscore the high preva-

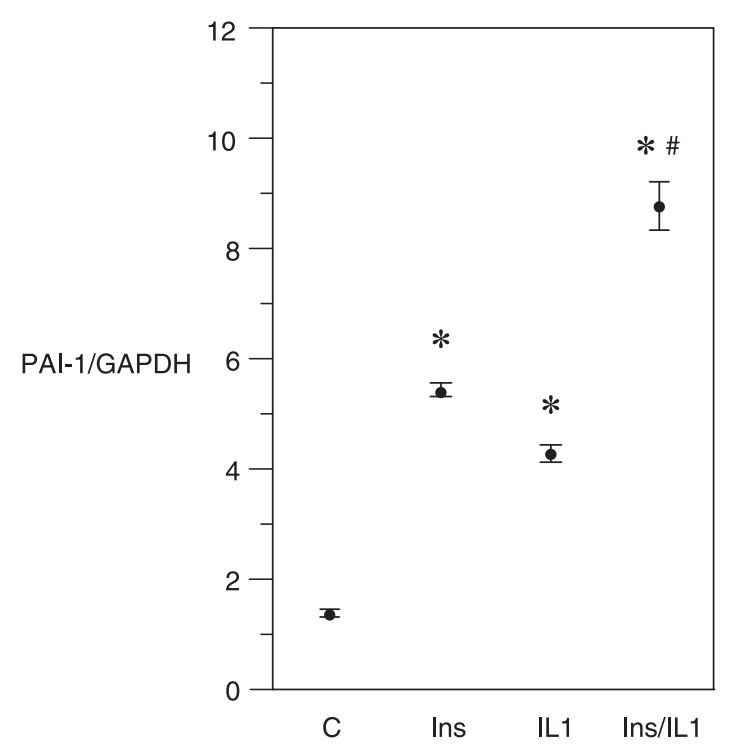

Fig. 7. Quantitative RT-PCR analysis of the combined effects of insulin and IL- $1 \beta$ on the amount of endogenous PAI1 mRNA. HepG2 cells were treated with insulin (Ins; $10 \mathrm{nM}, 48 \mathrm{~h}$ ), IL-1 $\beta$ (IL1; $1 \mathrm{nM}, 48 \mathrm{~h}$ ), or in combination. Then total RNA was extracted and applied for Real-Time RT-PCR using TaqMan probes specific to human PAI-1 mRNA. $* \mathrm{P}<0.05$ vs. vehicle group $(\mathrm{C})$. ${ }^{\#} \mathrm{P}<0.05$ vs. insulin alone group.

lence of thrombotic disorders in the metabolic syndrome. It has long been known that hypercoagulation and thrombosis are associated frequently with obesity. Expression of PAI-1 and fibrinogen are known to be increased in animal models of obesity [24, 25]. In ob/ob mice, Alessi et al. [25] reported that hepatic PAI-1 expression is higher than in adipose tissue and had a good correlation with plasma PAI-1 level, and Klover et al. [26] showed that neutralization of IL-6 significantly reduced hepatic fibrinogen mRNA levels. In human, plasma levels of PAI-1, fibrinogen, and CRP are elevated in patients with the metabolic syndrome [27-29]. Furthermore, Wannamethee et al. [30] have recently shown the inter-relationship between IL-6 and the PAI-1 and fibrinogen as well as CRP in patients with metabolic syndrome. The relationship between hyperinsulinemia and hypercoagulability is also reported [31], and the compensatory hyperinsulinemia in the insulin-resistant state may be responsible for the pathogenesis of the disorder [10]. In this sense, clinicians should be aware of the synergistic risk of thrombotic disorders in obese patients with hyperinsulinemia and with abdominal fat accumulation associated with proinflammatory cytokines. 


\section{References}

1. Reaven GM (2005) Compensatory hyperinsulinemia and the development of an atherogenic lipoprotein profile: the price paid to maintain glucose homeostasis in insulin-resistant individuals. Endocr Metab Clin North Am 34: 49-62.

2. Kashyap SR, Defronzo RA (2007) The insulin resistance syndrome: physiological considerations. Diabet Vascul Dis Res 4: 13-19.

3. Matsuzawa Y (2006) Therapy Insight: adipocytokines in metabolic syndrome and related cardiovascular disease. Nat Clin Pract Cardiovasc Med 3: 35-42.

4. Nieuwdorp M, Stroes ES, Meijers JC, Büller H (2005) Hypercoagulability in the metabolic syndrome. Curr Opi Pharmacol 5: 155-159.

5. Aoki Y, Iwasaki Y, Katahira M, Oiso Y, Saito H (1997) Regulation of the rat proopiomelanocortin gene expression in AtT-20 cells. I: Effects of the common secretagogues. Endocrinology 138: 1923-1929.

6. Nigro J, Osman N, Dart AM, Little PJ (2006) Insulin resistance and atherosclerosis. Endocr Rev 27: 242 259.

7. Nawano M, Ueta K, Oku A, Arakawa K, Saito A, Funaki M., Anai M, Kikuchi M, Oka Y, Asano T (1999) Hyperglycemia impairs the insulin signaling step between $\mathrm{PI}_{3}$-kinase and $\mathrm{Akt} / \mathrm{PKB}$ activations in ZDF rat liver. Biochem Biophys Res Commun 266: $252-256$.

8. Jiang ZY, Lin YW, Clemont A, Feener EP, Hein KD, Igarashi M, Yamauchi T, White MF, King GL (1999) Characterization of selective resistance to insulin signaling in the vasculature of obese Zucker $(\mathrm{fa} / \mathrm{fa})$ rats. $J$ Clin Invest 104: 447-457.

9. Yamaguchi K, Higashiura K, Ura N, Murakami H, Hyakukoku M, Furuhashi M, Shimamoto K (2003) The effect of tumor necrosis factor-alpha on tissue specificity and selectivity to insulin signaling. Hypertens Res 26: 389-396.

10. Wang CC, Goalstone ML, Draznin B (2004) Molecular mechanisms of insulin resistance that impact cardiovascular biology. Diabetes 53: 2735-2740.

11. Draznin B (2006) Molecular mechanisms of insulin resistance: serine phosphorylation of insulin receptor substrate-1 and increased expression of p85alpha: the two sides of a coin. Diabetes 55: 2392-2397.

12. Dawson SJ, Wiman B, Hamsten A, Green F, Humphries S, Henney AM (1993) The two allele sequences of a common polymorphism in the promoter of the plasminogen activator inhibitor-1 (PAI-1) gene respond differently to interleukin-1 in HepG2 cells. $J$ Biol Chem 268: 10739-10745.

13. Schmidt A, Vogel R, Holloway MK, Rutledge SJ, Friedman O, Yang Z, Rodan GA, Friedman E (1999) Transcription control and neuronal differentiation by agents that activate the LXR nuclear receptor family. Mol Cell Endocrinol 155: 51-60.

14. Agrawal A, Cha-Molstad H, Samols D, Kushner I (2001) Transactivation of C-reactive protein by IL-6 requires synergistic interaction of CCAAT/enhancer binding protein beta (C/EBP beta) and Rel p50. J Immunol 166: 2378-2384.

15. Voleti B, Agrawal A (2005) Regulation of basal and induced expression of $\mathrm{C}$-reactive protein through an overlapping element for OCT-1 and NF-kappaB on the proximal promoter. J Immunol 175: 3386-3390.

16. Iwasaki Y, Kambayashi M, Asai M, Yoshida M, Nigawara T, Hashimoto K (2007) High glucose alone, as well as in combination with proinflammatory cytokines, stimulates nuclear factor kappa-B-mediated transcription in hepatocytes in vitro. J Diabet Complicat 21: 56-62.

17. Vermeulen L, De Wilde G, Notebaert S, Vanden Berghe W, Haegeman G (2002) Regulation of the transcriptional activity of the nuclear factor- $\mathrm{kB}$ p65 subunit. Biochem Pharmacol 64: 963-970.

18. Vermeulen L, De Wilde G, Van Damme P, Vanden Berghe W, Haegeman G (2003) Transcriptional activation of the NF-kappaB p65 subunit by mitogen-and stress-activated protein kinase-1 (MSK1). EMBO J 22: 1313-1324.

19. Zhang Z, Fuentes NL, Fuller GM (1995) Characterization of the IL-6 responsive elements in the gamma fibrinogen gene promoter. $J$ Biol Chem 270: $24287-$ 24291.

20. Guo B, Inoki K, Isono M, Mori $\mathrm{H}$, Kanasaki K, Sugimoto T, Akiba S, Sato T, Yang B, Kikkawa R, Kashiwagi A, Haneda M, Koya D (2005) MAPK/AP-1-dependent regulation of PAI-1 gene expression by TGF-beta in rat mesangial cells. Kidney Int 68: 972-984.

21. Dimova EY, Kietzmann T (2006) The MAPK pathway and HIF-1 are involved in the induction of the human PAI-1 gene expression by insulin in the human hepatoma cell line HepG2. Ann NY Acad Sci 1090: 355-367.

22. Mayer C, Gruber HJ, Landl EM, Pailer S, Scharnagl H, Truschnig-Wilders M, März W (2007) Rosuvastatin reduces interleukin-6-induced expression of C-reactive protein in human hepatocytes in a STAT3- and C/EBPdependent fashion. Int J Clin Pharmacol Ther 45: 319327.

23. Nishikawa $T$, Hagihara $K$, Serada $S$, Isobe $T$, Matsumura A, Song J, Tanaka T, Kawase I, Naka T, Yoshizaki K (2008) Transcriptional complex formation of c-Fos, STAT3, and hepatocyte NF-1alpha is essential for cytokine-driven C-reactive protein gene expression. J Immunol 180: 3492-3501.

24. Herbert JM, Bernat A, Chatenet-Duchène L (1999) Effect of ciprofibrate on fibrinogen synthesis in vitro 
on hepatoma cells and in vivo in genetically obese Zucker rats. Blood Coagul Fibrinolysis 10: 239-244.

25. Alessi MC, Bastelica D, Mavri A, Morange P, Berthet B, Grino M, Juhan-Vague I (2003) Plasma PAI-1 levels are more strongly related to liver steatosis than to adipose tissue accumulation. Arterioscler Thromb Vasc Biol 23: 1262-1268.

26. Klover PJ, Clementi AH, Mooney RA (2005) Interleukin-6 depletion selectively improves hepatic insulin action in obesity. Endocrinology 146: 3417-3427.

27. Ford ES (2003) The metabolic syndrome and C-reactive protein, fibrinogen, and leukocyte count: findings from the Third National Health and Nutrition Examination Survey. Atherosclerosis 168: 351-358.

28. Juhan-Vague I, Alessi MC, Mavri A, Morange PE
(2003) Plasminogen activator inhibitor-1, inflammation, obesity, insulin resistance and vascular risk. $J$ Thromb Haemost 1: 1575-1579.

29. Sutherland JP, McKinley B, Eckel RH (2004) The metabolic syndrome and inflammation. Metab Syndr Relat Disord 2: 82-104.

30. Wannamethee SG, Whincup PH, Rumley A, Lowe GD (2007) Inter-relationships of interleukin-6, cardiovascular risk factors and the metabolic syndrome among older men. J Thromb Haemostat 5: 1637-1643.

31. Nilsson B, Berne C, Korsgren O (2005) The recent finding that tissue factor is produced by the pancreatic islets constitutes a possible link between insulin resistance and cardiovascular disease. Am J Ther 12: 551554. 